\title{
Haematopoietic cancer and medical history: a multicentre case control study
}

Paolo Vineis, Paolo Crosignani, Carlotta Sacerdote, Arabella Fontana, Giovanna Masala, Lucia Miligi, Oriana Nanni, Valerio Ramazzotti, Stefania Rodella, Emanuele Stagnaro, Rosario Tumino, Clotilde Viganò, Carla Vindigni, Adele Seniori Costantini

\begin{abstract}
Background-Viruses (such as EpsteinBarr virus) and pathological conditions (mainly involving immunosuppression) have been shown to increase the risk of haematolymphopoietic malignancies. Other associations (diabetes, tonsillectomy, autoimmune diseases) have been inconsistently reported.
\end{abstract}

Methods-The association between different haematolymphopoietic malignancies (lymphomas, myelomas and leukaemias) and the previous medical history has been studied in a population-based casecontrol investigation conducted in Italy, based on face to face interviews to $\mathbf{2 6 6 9}$ cases and 1718 population controls (refusal rates $10 \%$ and $19 \%$, respectively). Controls were a random sample of the general population.

Results-Previous findings were confirmed concerning the association between non-Hodgkin's lymphoma (NHL) and lupus erythematosus (odds ratio, $\mathrm{OR}=8.4 ;$ 95\% CI 1.6, 45), tuberculosis $(\mathrm{OR}=1.6 ; 1.05,2.5)$ and hepatitis $(1.8 ; 1.4$, 2.3). An association was found also between NHL and maternal $(O R=2.8 ; 1.1$, 6.9) or paternal tuberculosis $(O R=1.7 ; 0.7$, 3.9). Odds ratios of $4.0(1.4,11.8)$ and 4.4 $(1.1,6.6)$ were detected for the association between NHL and Hodgkin's disease, respectively, and previous infectious mononucleosis, but recall bias cannot be ruled out. No association was found with diabetes, tonsillectomy and adenoidectomy. An association with malaria at young age and "low grade" lymphatic malignancies is suggested. One interesting finding was the observation of four cases of poliomyelitis among NHL patients, one among Hodgkin's disease and one among myeloid leukaemia patients, compared with none among the controls (Fisher's exact test for NHL and Hodgkin's disease, $p=0.03$, one tail).

Conclusions-Some of these findings are confirmatory of previous evidence. Other observations, such as the putative role of the polio virus and of malaria are new. A unifying theory on the mechanisms by which previous medical history may increase the risk of haematolymphopoietic malignancies is still lacking.

(F Epidemiol Community Health 2000;54:431-436)

Ospedale S Giovanni and

CPO-Piemonte, via Santen

7, I-10126 Torino, Italy

(paolo.vineis@UNITO.it)

Accepted for publication 16 September 1999
The aetiology of leukaemias and lymphomas is still largely unknown. The known risk factors (ionising radiation and benzene exposure for leukaemias; immunosuppression, HIV infection, pesticide exposure for non-Hodgkin's lymphomas (NHL)) explain only a small proportion of the cases that occur in the world. ${ }^{1}$

The previous disease history has been considered in several investigations, mainly for NHL. A more than 100-fold increased risk of NHL has been described among kidney and cardiac transplant recipients, receiving immunosuppressive therapy, even after only one year of latency. ${ }^{23}$ Among subjects with serious immunological disorders, including HIV infected populations, ${ }^{4}$ an excess of NHL has been reported. Infection with Helicobacter pylori has been described as a risk factor for gastric NHL, with relative risks in the order of six in prospective studies. ${ }^{5}{ }^{6}$ Malaria has been associated with Burkitt's lymphoma in African children, ${ }^{78}$ in particular in association with infection with the Epstein-Barr virus (EBV). EBV has also been suspected as a risk factor for NHL or Hodgkin's disease (HD), in particular in serological studies on anti-EBV antibodies. ${ }^{9-11}$ The EBV genome has been found as an episome in Reed-Sternberg cells that are typical of HD. ${ }^{12}{ }^{13}$ Other infectious diseases or infection related conditions have also been associated with malignant lymphomas, in particular tuberculosis ${ }^{14}$ or the BCG vaccine, ${ }^{15}$ and hepatitis C. ${ }^{16-18}$

Non-infectious conditions that have been associated with increased risks of NHL are coeliac disease, ${ }^{19} 20$ systemic lupus, ${ }^{21} 22$ eczema, ${ }^{14}{ }^{23}$ rheumatoid arthritis, ${ }^{24-26}$ dermatitis herpetiformis ${ }^{27}$ and allergies. ${ }^{28}{ }^{29}$ Diabetes has been reported as a risk factor for NHL by some authors ${ }^{30-32}$ but not by others. ${ }^{33}$ A few studies have described an excess of HD among children who underwent tonsillectomy, but others were negative (for a review see Mueller ${ }^{34}$ ).

Findings on the association between previous disease history and leukaemias or myelomas are contradictory. ${ }^{35-37}$

At the moment there is no unifying theory on the mechanisms by which different diseases can increase the risk of different haematolymphopoietic malignancies. Viruses can exert a role by inserting their genome in the lymphatic cells, while other agents can act by impairing the immune system. For example, malaria has a strong immunosuppressive effect. ${ }^{8}$

While the incidence of other haematolymphopoietic malignancies is stable, NHL show increasing incidence (by $3-4 \%$ per year) in Western countries. ${ }^{38}$ 
Table 1 Selected characteristics of interviewed cases and controls

\begin{tabular}{|c|c|c|c|c|}
\hline \multirow[b]{2}{*}{ Men } & \multicolumn{2}{|c|}{$\begin{array}{l}\text { Cases } \\
(n=2669)\end{array}$} & \multicolumn{2}{|c|}{$\begin{array}{l}\text { Controls } \\
(n=1718)\end{array}$} \\
\hline & 1486 & $(55.7)$ & 890 & $(52)$ \\
\hline Women & 1183 & $(44.3)$ & 828 & $(48)$ \\
\hline Mean age (y) & 56.1 & & 54.9 & \\
\hline Duration of interview (min) & 62.1 & & 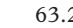 & \\
\hline $\begin{array}{l}\text { Duration of interview divided } \\
\text { by number of jobs held }\end{array}$ & 30 & & 30 & \\
\hline Incomplete interviews & 129 & (5) & 51 & (3) \\
\hline \multicolumn{5}{|l|}{ Years of school } \\
\hline$<6$ & 1231 & $(46)$ & 749 & $(44)$ \\
\hline $6-8$ & 588 & (22) & 401 & (23) \\
\hline $9-13$ & 552 & $(21)$ & 359 & (21) \\
\hline $14+$ & 265 & (10) & 194 & (11) \\
\hline missing & 33 & (1) & 15 & (1) \\
\hline Face to face interviews & 2567 & (96) & 1628 & (95) \\
\hline Telephone & 102 & (4) & 90 & (5) \\
\hline Home interviews & 1702 & $(64)$ & 1343 & (78) \\
\hline Hospital interviews & 642 & (24) & 29 & $(0.2)$ \\
\hline Other (epidemiology unit) & 325 & (12) & 346 & $(21)$ \\
\hline
\end{tabular}

Data shown in parentheses are percentages.

We describe a large population-based casecontrol study in Italy in which the medical history has been considered.

\section{Methods}

We have conducted a population-based casecontrol study. The areas included in the study are 11 Italian areas with different demographic and socioeconomic characteristics (town of Torino, provinces of Varese, Novara, Vercelli, Alessandria, Imperia, Ragusa, Siena, Forlì, Verona, and Firenze). Some are urban, industrial areas (Torino, Varese, Firenze), while the

Table 2 Distribution of the cases and controls by age, gender and diagnostic categories

\begin{tabular}{lrrrrrrr}
\hline \multicolumn{2}{c}{ Cases } & & & & & & \\
\cline { 2 - 6 } & NHL & \multicolumn{1}{c}{ HD } & MM & LL & ML & Other & Controls \\
\hline Age & & & & & & & \\
20-34 & 95 & 155 & 1 & 17 & 26 & 8 & 228 \\
$35-44$ & 133 & 55 & 10 & 18 & 32 & 11 & 197 \\
$45-54$ & 249 & 54 & 38 & 27 & 54 & 18 & 302 \\
$55-64$ & 435 & 62 & 82 & 91 & 92 & 23 & 467 \\
65-74 & 476 & 28 & 132 & 108 & 109 & 30 & 524 \\
Gender & 777 & 188 & 129 & 161 & 185 & 45 & 890 \\
Men & 611 & 166 & 134 & 100 & 128 & 45 & 828 \\
Women & 1388 & 354 & 263 & 261 & 313 & 90 & 1718 \\
Totals & & & & & \\
\hline
\end{tabular}

NHL = non-Hodgkin's lymphoma (excluding chronic lymphocytic leukaemia); HD = Hodgkin's disease; $\mathrm{MM}=$ multiple myeloma $\mathrm{LL}=$ lymphocytic leukaemia $\mathrm{ML}=$ myeloid leukaemia. Two HD cases have been excluded because the medical history was missing.

Table 3 Number of exposed cases, age and sex adjusted ORs and 95\% CI (all cases $v$ controls) for selected previous pathological conditions. $A=$ only subjects who recalled the date of occurrence; $B=$ all subjects

\begin{tabular}{|c|c|c|c|c|}
\hline & \multicolumn{2}{|l|}{$A$} & \multicolumn{2}{|l|}{$B$} \\
\hline & Number & OR $(95 \% C I)$ & Number & OR $(95 \% C I)$ \\
\hline Herpes genitalis & 25 & $1.1(0.6,2.1)$ & 32 & $1.4(0.8,2.6)$ \\
\hline Herpes labialis & 462 & $0.9(0.7,1.0)$ & 775 & $1.0(0.9,1.2)$ \\
\hline Chickenpox & 744 & $0.9(0.8,1.1)$ & 1100 & $1.0(0.9,1.2)$ \\
\hline Eczema & 134 & $1.0(0.8,1.3)$ & 142 & $1.0(0.8,1.3)$ \\
\hline Psoriasis & 55 & $1.0(0.7,1.6)$ & 66 & $1.2(0.8,1.8)$ \\
\hline Allergies & 174 & $0.9(0.7,1.2)$ & 192 & $0.9(0.7,1.1)$ \\
\hline Hay fever & 127 & $0.7(0.5,0.9)$ & 137 & $0.7(0.6,0.9)$ \\
\hline Ulcerative colitis & 58 & $1.1(0.7,1.7)$ & 65 & $1.2(0.8,1.8)$ \\
\hline Lupus erythematosus & 8 & $5.1(0.8,32)$ & 8 & $5.2(0.6,41.4)$ \\
\hline Sclerodermia & 10 & $1.3(0.4,3.8)$ & 11 & $1.4(0.5,4.1)$ \\
\hline Infectious mononucleosis & 18 & $3.1(1.1,8.7)$ & 21 & $3.5(1.2,10.1)$ \\
\hline Hepatitis & 230 & $1.5(1.1,1.9)$ & 265 & $1.5(1.2,1.9)$ \\
\hline Tuberculosis & 73 & $1.4(0.9,2.1)$ & 74 & $1.4(0.9,2.1)$ \\
\hline Diabetes & 175 & $0.9(0.7,1.2)$ & 183 & $1.0(0.8,1.1)$ \\
\hline Tonsillectomy & 631 & $1.0(0.8,1.2)$ & 668 & $1.0(0.8,1.1)$ \\
\hline Adenoidectomy & 272 & $1.1(0.9,1.4)$ & 288 & $1.1(0.9,1.3)$ \\
\hline Malaria & 111 & $0.9(0.7,1.2)$ & 118 & $0.9(0.7,1.2)$ \\
\hline
\end{tabular}

others are mixed or rural areas. Overall, the study covered a population of approximately 7 million residents. Incidence rates for each of the disorders under investigation have been published from the 11 areas. ${ }^{39}$

In each centre, all the subjects suspect of being affected by leukaemia, lymphoma or multiple myeloma were identified through periodical surveys in the hospital departments where such cases are diagnosed (ICD-9 codes 200 through 208). Only newly diagnosed cases occurring in the study period (1990-1993) were included (both sexes, aged 20-74, residents of the areas under study). In each hospital department a reference physician was identified and cooperated in case finding. Case ascertainment was based also on periodical surveys in the pathology departments andwhere available - in the archives of Cancer Registries. In addition, Cancer Institutes and departments of haematology and pathology located in Milano, Roma, Pavia, Bologna and Genova (that is, external to the study areas) were periodically surveyed. A timely recruitment was necessary to keep as high as possible the proportion of cases who were alive at interview. All suspect cases were identified and interviewed; the case status was further evaluated after interview, with direct access to the clinical record or the histological diagnosis, or both. Case ascertainment was complete, as a comparison with historical data of Cancer Registries in the same areas suggests. The level of case ascertainment did not vary across centres.

For case classification-based on immunocytochemical techniques-we used the Working Formulation proposed by the National Cancer Institute for $\mathrm{NHL}^{40}$ (used here in a simplified version: low, intermediate and high grade of malignancy), and the Rye classification for HD. ${ }^{41} \mathrm{~A}$ distinction between $\mathrm{B}$ and $\mathrm{T}$ cell origin was made.

The control group is formed by a random sample of the population resident in each of the areas, aged 20-74. The sample was stratified according to five year age groups and sex, and its size was equal to the number of cases in the largest diagnostic group (NHL+chronic lymphocytic leukaemias). Procedures for control sampling were of two types. In the provinces of Forli and Ragusa and in the city of Firenze the computerised and regularly updated demographic files were used. These files are maintained under national law in all cities and towns throughout Italy. They are central population registries that serve such multiple purposes as voter registration, car insurance, school eligibility, and pensions. They are well validated as epidemiological data sources, are continually updated, and highly accurate. In the other areas (where the demographic files were not accessible to the investigators) sampling took place through the files of the National Health Service, which are updated every six months.

Information about the known or suspect risk factors (including a very detailed occupational history, smoking, residential history and family history) for the disorders under investigation 
Table 4 Distribution of haematolymphopoietic malignancies by selected diseases. Men and women. Age and gender adjusted odds ratios (OR) and 95\% confidence intervals (CI). Only cases and controls who recalled the date at diagnosis of the selected diseases are shown

\begin{tabular}{llllll}
\hline & NHL & $H D$ & $M M$ & $L L$ & $L M$ \\
\hline Herpes genitalis & $0.8(0.3,1.7)$ & $2.1(0.7,5.8)$ & $2.3(0.8,6.5)$ & $1.5(0.5,5.2)$ & $0.4(0.05,2.6)$ \\
Herpes labialis & $1.0(0.8,1.1)$ & $0.8(0.6,1.1)$ & $0.8(0.6,1.2)$ & $1.3(0.9,1.8)$ & $0.5(0.4,0.8)$ \\
Chickenpox & $1.1(0.9,1.3)$ & $0.8(0.5,1.1)$ & $0.8(0.5,1.2)$ & $0.7(0.5,1.0)$ & $0.9(0.6,1.3)$ \\
Eczema & $1.2(0.9,1.6)$ & $0.7(0.4,1.3)$ & $0.6(0.3,1.3)$ & $1.2(0.7,2.1)$ & $0.8(0.4,1.4)$ \\
Psoriasis & $1.1(0.7,1.8)$ & $1.0(0.4,2.4)$ & $0.4(0.1,1.6)$ & $1.5(0.7,3.4)$ & $0.8(0.3,2.1)$ \\
Allergies & $0.9(0.7,1.3)$ & $0.9(0.5,1.4)$ & $1.1(0.6,1.8)$ & $1.0(0.6,1.6)$ & $0.7(0.4,1.2)$ \\
Hay fever & $0.7(0.5,1.0)$ & $0.5(0.3,0.8)$ & $0.8(0.4,1.5)$ & $1.1(0.6,1.9)$ & $0.45(0.2,0.9)$ \\
Ulcerative colitis & $1.4(0.9,2.2)$ & $0.7(0.2,2.3)$ & $0.8(0.3,2.1)$ & $1.1(0.4,2.6)$ & $0.8(0.3,2.0)$ \\
Lupus erythematosus & $8.4(1.6,45)$ & - & - & - & - \\
Sclerodermia & $1.7(0.6,5.3)$ & - & $1.4(0.2,11.9)$ & - & \\
\hline
\end{tabular}

Abbreviations as in table 2 .

was collected through person to person interviews. Interviews were done preferentially at the home of the interviewee. The same procedures were followed for cases and controls. The only exception was represented by interviews to cases affected by acute leukaemia and seriously ill, which were mostly done in the hospital.

Techniques for the motivation of subjects to participate, such as contacts with the general practitioners, were applied. They were particularly successful in keeping the response rate high.

The interview was face to face and lasted approximately one hour. The personnel in charge of the interviews was trained, specifically for this study, through a residential three day course at the Siena University. A manual for interviewers has been prepared. Both the programme of the course and the manual are available on request. Accuracy and standardidation of the interview procedures was periodically verified by the epidemiologist responsible for the study in each centre.

We have investigated the entire medical history for the following diseases: measles, rubeola, chickenpox, pertussis, herpes zoster, herpes labialis, herpes genitalis, mumps, infectious hepatitis, infectious mononucleosis, tuberculosis, malaria, other infectious diseases (specified by the interviewee), hay fever, allergic asthma, other (specified) allergies, peptic ulcer, ulcerative colitis, glutine intolerance, Crohn's disease, other (specified) digestive diseases, diabetes and other (specified) metabolic diseases, rheumatoid arthritis, lupus erythema-

Table 5 Distribution of cases and controls by infectious mononucleosis (IM), by gender, age at onset, latency of IM and years of school. Cases with unknown age at onset of IM are excluded. Age adjusted odds ratios and 95\% confidence intervals

\begin{tabular}{lllllllll}
\hline IM & Controls & NHL & HD & $M M$ & LL & ML & Other \\
\hline Men & 883 & 748 & 182 & 122 & 160 & 176 & 44 \\
No & 2 & 4 & 5 & 0 & 0 & 1 & 0 \\
Yes & & & & & & & \\
Women & 816 & 594 & 159 & 130 & 98 & 121 & 43 \\
No & 2 & 6 & 2 & 0 & 0 & 0 & 0 \\
Yes & 1.0 & 4.0 & 4.4 & - & - & - & - \\
Age adjusted ORs & - & $(1.4$, & $(1.1$, & & & & \\
$95 \%$ CI & & $11.8)$ & $16.6)$ & & & & \\
Latency between IM and & & OR & $95 \%$ CI & & & & \\
$\quad$ lymphoma & & & & & & & & \\
$<10$ & & 8.1 & $1.4,46$ & & & & \\
$10+$ & Cases/controls & OR & $95 \%$ CI & & & & \\
Years of school & with IM & & & & & & \\
& $7 / 3$ & 2.2 & $0.6,8.5$ & & & & \\
$<14$ & $10 / 1$ & 9.8 & $1.9,51$ & & & & \\
$14+$ & & & & & &
\end{tabular}

Abbreviations as in table 2. tosus, periarteritis nodosa, sclerodermia, other (specified) osteomuscular diseases, urticaria, eczema, psoriasis, other skin allergies, and other (specified) relevant diseases. Only diseases that had been formally diagnosed by a physician were considered. For each disease the date at onset was investigated, except for those under the label "other, specified".

The overall refusal rate was $10 \%$ among cases and 19\% among controls. Further reasons for non-participation included subjects who were too ill, mental disease, subjects who were eligible but lived abroad and subjects who were not found on the telephone or at home after five attempts ( $7 \%$ cases and $6 \%$ controls). Further details on methods are given in a previous paper. ${ }^{42}$

\section{DATA ANALYSES}

Data analyses were performed with SAS for personal computer. Data editing, checks of logical consistency and error correction were performed using ad hoc programs. Point estimates of odds ratios and the corresponding confidence intervals were computed according both to stratified (Mantel-Haenszel) and multivariate procedures (logistic regression), taking into account relevant potential confounders (age, social class, education, study centre). ${ }^{43}$ As only the inclusion of age and sex modified the estimates, we show age and sex adjusted odds ratios. Comparisons were made between each diagnostic group and the controls as a whole. Fisher's exact test was used when the number of expected subjects was lower than 5 .

Other risk factors (smoking, occupation, residential history) are considered in separate manuscripts (in preparation).

\section{CONTROL OF RECALL BIAS}

The history of previous diseases is particularly prone to recall bias. Cases tend to be more accurate in speculating about all possible causes of their disease. Recall bias is expected to be stronger in two circumstances: (a) when the diagnosis has not been made by a physician (but we have excluded such information during the interview), and (b) when the subject claims they have had a specific disease, but does not recall the date of first diagnosis. The latter type of bias is expected to be more important for mild than for serious diseases. Examples of serious diseases that are unlikely to be affected by major recall bias are lupus erythematosus, diabetes, malaria (which was endemic in some 
Table 6 Distribution of haematolymphopoietic malignancies by selected diseases or surgical interventions. Men and women. Age and gender adjusted odds ratios (OR) and 95\% confidence intervals (CI)

\begin{tabular}{|c|c|c|c|c|c|c|}
\hline & Controls & NHL & $H D$ & $M M$ & $L L$ & $M L$ \\
\hline \multicolumn{7}{|l|}{ Infectious hepatitis } \\
\hline yes & 107 & 141 & 23 & 23 & 25 & 15 \\
\hline no & 1585 & 1193 & 325 & 229 & 228 & 280 \\
\hline OR & 1.0 & 1.8 & 1.1 & 1.5 & 1.7 & 0.8 \\
\hline $95 \%$ CI & & $1.4,2.3$ & $0.6,1.8$ & $0.9,2.4$ & $1.1,2.6$ & $0.4,1.4$ \\
\hline Tuberculosis & Controls & NHL & $H D$ & $M M$ & $L L$ & $M L$ \\
\hline yes & 34 & 48 & 9 & 5 & 4 & 6 \\
\hline no & 1677 & 1318 & 344 & 252 & 254 & 298 \\
\hline OR & 1.0 & 1.6 & 2.6 & 0.7 & 0.7 & 0.9 \\
\hline $95 \%$ CI & & $1.05,2.5$ & $1.1,6.1$ & $0.3,1.8$ & $0.2,1.8$ & $0.4,2.2$ \\
\hline Diabetes & & $N H L$ & $H D$ & $M M$ & $L L$ & $M L$ \\
\hline OR & & 1.1 & 0.9 & 0.7 & 0.9 & 0.8 \\
\hline \multirow[t]{2}{*}{$95 \% \mathrm{CI}$} & & $(0.8,1.4)$ & $(0.4,1.7)$ & $(0.4,1.1)$ & $(0.6,1.5)$ & $(0.6,1.05)$ \\
\hline & & Controls (n) & NHL (n) & OR $(95 \% \mathrm{CI})$ & & \\
\hline$<10$ years before NHL & & 52 & 53 & $0.9(0.6,1.3)$ & & \\
\hline $10-20$ & & 37 & 34 & $1.0(0.6,1.6)$ & & \\
\hline $20+$ & & 25 & 23 & $1.0(0.5,1.7)$ & & \\
\hline Tonsillectomy & Controls & $N H L$ & $H D$ & $M M$ & $L L$ & $M L$ \\
\hline yes & 434 & 346 & 108 & 45 & 48 & 61 \\
\hline no & 1270 & 995 & 239 & 212 & 206 & 244 \\
\hline OR & 1.0 & 1.1 & 1.0 & 0.8 & 0.8 & 0.8 \\
\hline $95 \% \mathrm{CI}$ & & $0.9,1.3$ & $0.7,1.3$ & $0.6,1.2$ & $0.6,1.1$ & $0.6,1.1$ \\
\hline Adenoidectomy & Controls & $N H L$ & $H D$ & $M M$ & $L L$ & $M L$ \\
\hline yes & 171 & 147 & 49 & 21 & 17 & 28 \\
\hline no & 1524 & 1199 & 295 & 235 & 241 & 276 \\
\hline OR & 1.0 & 1.2 & 1.0 & 1.2 & 0.7 & 1.0 \\
\hline $95 \% \mathrm{CI}$ & & $0.9,1.5$ & $0.7,1.4$ & $0.7,1.9$ & $0.4,1.3$ & $0.6,1.6$ \\
\hline
\end{tabular}

Abbreviations as in table 2.

Italian areas in the past) and surgical operations such as tonsillectomy or adenoidectomy. We have considered the potential for recall bias by including only the subjects who recalled the date of occurrence of each disease.

\section{Results}

Table 1 gives selected information on the interviewed cases and controls, and table 2 the distribution by gender, age and the diagnostic categories of the cases.

A previous paper has been devoted to the association between peptic ulcer and gastric NHL. ${ }^{42}$

Table 3 shows odds ratios (OR) and 95\% confidence intervals (CI) for selected diseases (those with at least five cases exposed). The analyses are shown according to both the conservative criterion of analysing only the subjects who were able to recall the date of first diagnosis (A), and to a broader criterion of inclusion (B). The differences between the two criteria are marginal; only for herpes labialis and chicken pox, as expected, there is a large discrepancy between the two criteria, but this

Table 7 Distribution of cases and controls by age at onset of malaria. Men and women

\begin{tabular}{|c|c|c|c|c|c|c|}
\hline & Controls & $N H L$ & $H D$ & $M M$ & $L L$ & $M L$ \\
\hline \multicolumn{7}{|l|}{ Malaria } \\
\hline Before age 10 & 15 & 9 & 1 & 4 & 7 & 2 \\
\hline Age $10-20$ & 34 & 24 & 1 & 5 & 10 & 4 \\
\hline Age $20+$ & 25 & 18 & 1 & 12 & 6 & 5 \\
\hline Never & 1636 & 1320 & 349 & 237 & 234 & 291 \\
\hline \multicolumn{7}{|c|}{ Odds ratios and $95 \%$ CI } \\
\hline Malaria & Controls & NHL & $H D$ & $M M$ & $L L$ & $M L$ \\
\hline Before age 10 & 1.0 & 0.6 & 0.5 & 1.1 & 2.9 & 0.7 \\
\hline $95 \% \mathrm{CI}$ & & $0.2,1.4$ & $0.07,3.9$ & $0.3,4.2$ & $1.2,7.1$ & $0.2,2.9$ \\
\hline Age $10-20$ & 1.0 & 0.7 & 0.3 & 0.7 & 1.6 & 0.5 \\
\hline $95 \% \mathrm{CI}$ & & $0.4,1.3$ & $0.04,2.1$ & $0.3,1.9$ & $0.8,3.2$ & $0.1,1.4$ \\
\hline Age $20+$ & 1.0 & 0.7 & 0.8 & 1.9 & 1.2 & 0.8 \\
\hline $95 \% \mathrm{CI}$ & & $0.4,1.4$ & $0.1,6.2$ & $0.9,3.9$ & $0.5,3.1$ & $0.3,2.4$ \\
\hline \multicolumn{7}{|c|}{ Odds ratios and $95 \%$ CI } \\
\hline Malaria & Controls & \multicolumn{5}{|c|}{ Working Formulation "low grade" } \\
\hline Before age 10 & 1.0 & \multicolumn{5}{|c|}{$2.3(1.1,5.0)$} \\
\hline Age $10-20$ & 1.0 & \multicolumn{5}{|c|}{$1.3(0.7,2.3)$} \\
\hline Age $20+$ & 1.0 & \multicolumn{5}{|c|}{$1.0(0.4,2.1)$} \\
\hline
\end{tabular}

Abbreviations as in table 2 . does not affect the risk estimates. Statistically significant OR, after exclusion of unknown dates, were observed for hay fever (associated with a protective effect), infectious mononucleosis and hepatitis.

Table 4 gives the age adjusted OR and 95\% CI for each diagnostic category within haematolymphopoietic malignancies. A statistically significant association is evident only for lupus erythematosus and NHL (OR=8.4; 95\% CI $1.6,45)$. A negative association with hay fever is suggested; this is statistically significant for HD and myeloid leukaemia.

Table 5 describes the data for infectious mononucleosis (IM). As in the previous table, we have excluded subjects who were not able to locate the onset of IM in time. A relative risk of about four was found for both NHL and HD. A positive association was detected between a higher educational level and the risk of NHL or HD among the subjects who reported previous IM.

Other confirmatory findings from our study concern a history of hepatitis and of tuberculosis and the risk of NHL and lymphocytic leukaemia (table 6). Also HD was increased among subjects who reported tuberculosis. In addition, tuberculosis as the cause of death in the mother was strongly associated with NHL $(\mathrm{OR}=2.8$; 95\% CI 1.1, 6.9; based on 15 cases and 6 controls), while the association with father's tuberculosis was weaker $(\mathrm{OR}=1.7 ; 0.7$, 3.9; based on 13 cases and 8 controls). No similar association was detected with HD.

Our study does not confirm previous suggestions concerning NHL and diabetes (table 6). We have considered different latency periods between the onset of diabetes and the risk of NHL, but no association was found. Also tonsillectomy and adenoidectomy showed no relation with any of the diseases included in our study (table 6). 
Table 7 suggests that a history of malaria increases the risk of lymphatic leukaemias and of "low grade" B cell malignancies (according to the Working Formulation), two categories partially overlapping. The risk is associated, in fact, only with malaria at young age. Malaria was endemic in several Italian areas until the end of the second world war.

Finally, one interesting finding was the observation of four cases of poliomyelitis among NHL patients, one among HD and one among myeloid leukaemia patients, compared with none among the controls (Fisher's exact test for NHL+HD, $\mathrm{p}=0.03$, one tail). These cases had no peculiar distribution by histological findings or anatomic site. They lived in different towns, there was no evident link among them, and no reasonable suspicion of recall bias.

Estimates were not modified or confounded by residence (urban/rural), education or centre.

\section{Discussion}

The incidence of NHL is increasing in Western societies, while HD, leukaemias and myelomas are stable. ${ }^{1}$ NHL have been associated with immunosuppression, particularly among patients who have had a transplant and HIV carriers. It can be hypothesised that exposure to mild immunosuppressants can also increase the risk of NHL. ${ }^{44}$ Some viruses-namely, EBV - have been implicated in the aetiology of NHL and HD.

We have conducted a large study on haematolymphopoietic malignancies and medical history. Merits of our study are the large sample size, the population design (with controls randomly drawn from the general population), the low refusal rate, and the overall good quality of interviews, collected by trained interviewers. The main limitation is related to the nature of the information on previous diseases, exclusively based on interviews with no objective clinical data. However, the methods we used to limit recall bias (see Methods section) reassure us about the credibility of the findings. Despite the multiple comparisons, the low number of statistically significant associations is rather suprising.

Our study confirms an association of NHL and HD with IM. Interestingly, the association is stronger among subjects belonging to higher social groups, defined on the basis of education. We cannot rule out that this finding is attributable to recall bias-that is, more accurate recall of IM infection by subjects belonging to higher social groups. In fact, it is probable that more educated people have physicians or researchers among their friends, and may be more receptive to speculations about causes. A similar finding has been reported for the association between gastric NHL and peptic ulcer (infection with $H$ pylori); in that case recall bias is highly unlikely. ${ }^{42}$ For both conditions (peptic ulcer and IM), the infectious agent is extremely common: $90 \%$ of adults living in Western societies are immunised against EBV; about $40-45 \%$ of Italians are immunised against $H$ pylori. ${ }^{42}$ Some late
KEY POINTS

- The incidence of non-Hodgkin's lymphomas (NHL) is increasing in Western societies, while Hodgkin's disease (HD), leukemias and myelomas are more stable.

- The aetiology of such conditions is still largely unknown.

- We have conducted a large sample size study, with a population design and low refusal rate

- Chronic infections or parasitic diaseases, such as tuberculosis, hepatitis or malaria, can increase the risk of cancer, including NHL.

- Chronic infections increase the production of oxygen radicals that cause oxidative DNA damage; other conditions, such as malaria, can act by causing a chronic immunosuppressive state

- An unexpected finding in the study was the observation of five lymphomas (four NHL, one HD), one case of myeloid leukemia and no controls who had had poliomyelitis.

- Other diseases such as diabetes, inconsistently reported in previous studies as being associated with NHL, are not shown in excess in this study.

event associated with higher social class could trigger the development of gastric NHL or, respectively, lymphnodal NHL. It can be speculated that early $H$ pylori or EBV infection creates local immunological protection, while late infection-more typical of higher social groups-would entail an increased risk of lymphoma.

Chronic infections can increase the risk of cancer. ${ }^{46}{ }^{47}$ Several mechanisms have been proposed for this finding. In particular, it has been speculated that chronic infections increase the production of oxygen radicals that cause oxidative DNA damage. ${ }^{46}$ This mechanism might explain the association we have found between tuberculosis and NHL and HD, and between NHL and hepatitis (we do not have information, however, about the clinical characteristics and course of hepatitis). The association between parental death from tuberculosis and NHL is more difficult to explain.

Malaria has been identified as a risk factor for Burkitt's lymphoma in African children, particularly in interaction with EBV. To the best of our knowledge, an association between malaria and lymphatic malignancies has not been reported before from Western countries. Malaria causes a chronic immunosuppressive state $^{8}$ but it could also act by the formation of reactive oxygen species and DNA damage.

An unexpected finding was the observation of five lymphomas (four NHL, one HD), one case of myeloid leukaemia and no controls who had had poliomyelitis $(p=0.03$, one tail exact test, for NHL+HD). This observation is unlikely to be attributable to recall bias, as poliomyelitis is a very severe disease. It might shed light on still unknown relations between viral infections and lymphomas. HD has an age 
distribution that is similar to that of poliomyelitis, and a similar pathogenetic process has been invoked (the so called polio model for HD). ${ }^{34}$

Finally, we did not confirm the role of diabetes in NHL aetiology, as reported recently by some researchers but not by others. The lack of an association cannot be explained by severe pitfalls. Our study was populationbased, the response rate was particularly high and the vast majority of interviews were conducted face to face by trained personnel. Random misclassification because of inaccuracies in the recall of the disease history is possible, although diabetes is a condition that is usually well known to the patients.

Unit of Cancer Epidemiology, Ospedale S Giovanni and CPOPiemonte, Torino: P Vineis, C Sacerdote; Unit of Epidemiology, National Cancer Institute, Milano: P Crosignani, C Viganò Local Health Unit, Novara: A Fontana; Unit of Epidemiology, National Cancer Institute, Genova: G Masala, Emanuele Stagnaro; Unit of Epidemiology, Centre for Oncologic Preven tagnaro, Unit , tion (CSPO), Firenze: G Masala, L Miligi, A Seniori Costantini; Istituto Oncologico Romagnolo, Forli: O Nanni; National Cancer Institute, Istituto Regina Elena, Roma: V Ramazzotti; Azienda Ospedaliera, Verona: S Rodella; Cancer Registry, R Tumino; Institute of Pathology, University of Siena: C R Tumin

Vindigni.

We thank professors Luigi Resegotti, Giorgio Palestro (Torino) and Luciano Fiore Donati (Verona) for suggestions and encouragement. The kind cooperation of the clinical department staff involved in patient recruitment is acknowledged. We are grateful to Olof Nyren (Karolinska Institutet, Stockholm) for careful reading of the paper.

Funding: the Italian multicentre study on haematolymphopoietic malignancies has been funded by the US National Cance Institute (CA51086).

Conflicts of interest: none.

1 Levine PH, Hoover RN. The emerging epidemic of non-Hodgkin's lymphoma. Cancer Res 1992;52 (suppl.):5425-74s.

2 Kinlen LJ. Malignancy in autoimmune diseases. 7 Autoim mun 1992;5:363-71.

3 Kersey JH, Shapiro RS, Filipovich AH. Relationship of immunodeficiency to lymphoid malignancy. Pediatr Infect Dis $\mathcal{F} 1988 ; 7:$ S10-12.

4 Johnson CC, Wilcosky T, Kvale T, et al. Cancer incidence among an HIV-infected cohort. Am f Epidemiol 1997;146: 470-5.

5 Parsonnet J, Friedman GD, Vandersteen DP, et al. Helicobacter pylori infection and the risk of gastric Helicobacter pylori infection and the risk
carcinoma. N Engl f Med 1991;325:1127-31.

6 Nakamura S, Yao T, Aoyagi K, et al. Helicobacter pylori and primary gastric lymphoma. A histopathologic and primary gastric lymphoma. A histopathologic and immunohistoch

7 de Thé G. Epstein-Barr virus and Burkitt's lymphoma worlwide: the causal relationship revisited. In: Lenoir GM, O'Connor GT, Olweny CLM, eds. Burkitt's lymphoma: a human cancer model. IARC Scientific Publications no 60. Lyon, France: International Agency for Research on Cancer, 1985:65-76.

8 Morrow RH. Epidemiological evidence for the role of Falciparum Malaria in the pathogenesis of Burkitt's lymphoma. In: Lenoir GM, O'Connor GT, Olweny CLM, eds. Burkitt's lymphoma: a human cancer model. IARC Scientific Publications no 60. Lyon, France: International Agency for Research on Cancer, 1985

9 Mueller N, Mohar A, Evans A, et al. Epstein-Barr virus antibody patterns preceeding the diagnosis of non-Hodgkin's body patterns preceeding the diagnosis of
lymphoma. Int 7 Cancer 1991;49:387-93.

10 Mueller N, Mohar A, Evans A. Viruses other than HIV and non-Hodgkin's lymphoma. Cancer Res 1992;52 (suppl): $5479-81 \mathrm{~s}$

11 Young L, Alfieri C, Hennessey K, et al. Expression of Epstein-Barr virus transformation-associated genes in tissues of patients with EBV limphoproliferative disease. $N$ Engl F Med 1989;321:1080-5.

12 Herbst H, Steinbracher E, Niedobitek G, et al. Distribution and phenotype of Epstein-Barr virus-harboring cells in Hodgkin's disease. Blood 1992;80:484-91.

13 Herbst H, Niedobitek G. Epstein-Barr virus and Hodgkin's disease. Int f Clin Lab Res 1993;23:13-16.

14 Doody MM, Linet MS, Glass AG, et al. Leukemia, lymphoma, and multiple myeloma following selected medical conditions. Cancer Causes Control 1992;3:449-56.

15 Kendrick MA, Comstock GW. BCG vaccination and the subsequent development of cancer in humans. I Natl Cancer Inst 1981;66:431-37.
16 Ferri C, Caracciolo F, Zignego AL, et al. Hepatitis C virus infection in patients with non-Hodgkin's lymphoma. $\mathrm{Br} \mathcal{F}$ Haematol 1994:88:392-4.

17 Izumi T, Sasaki R, Miura Y, Okamoto H. Primary hepatosplenic lymphoma: association with hepatitis $\mathrm{C}$ virus infection. Blood 1996;87:5380-1.

18 Pioltelli P, Zehender G, Monti G, et al. HCV and non-Hodgkin lymphoma. Lancet 1996;347:624-5.

19 Holmes GKT, Stokes PL, Sorahan TM, et al. Coeliac disease, gluten-free diet, and malignancy. Gut 1976;17: 612-19.

20 Swinson CM, Coles EC, Slavin G, et al. Coeliac disease and malignancy. Lancet 1983;i:111-15.

21 Pettersson T, Pukkala E, Teppo L, et al. Increased risk of cancer in patients with systemic lupus erythematosus. Ann Rheum Dis 1992:51:437-9.

22 Mellemkjœr L, Andersen V, Linet MS, et al. Non-Hodgkin's lymphoma and other cancers among a cohort of patients with systemic lupus erythematosus. Arthritis Rheum 1997; 40:761-8.

23 Cartwright RA, McKinney PA, O'Brien C, et al. NonHodgkin's lymphoma: case-control epidemiological study in Yorkshire. Leuk Res 1988;12:81-8.

24 Isomäki HA, Hakulinen T, Joutsenlahti U. Excess risk of lymphomas, leukemia and myeloma in patients with rheumatoid arthritis. F Chronic Dis 1978;31:691-6.

25 Gridley G, McLaughlin JK, Ekbom A, et al. Incidence of cancer among patients with rheumatoid arthritis. 7 Natl Cancer Inst 1993;85:307-11.

26 Mellemkjoer L, Linet MS, Gridley G, et al. Rheumatoid arthritis and cancer risk. Eur f Cancer 1996;32:1753-7.

27 Sigurgeirsson B, Agnarsson BA, Lindelöf B. Risk of lymphoma in patients with dermatitis herpetiformis. $B M \mathcal{F}$ 1994;308:13-15.

28 Eriksson NE, Holmén A, Högstedt B, et al. A prospective study of cancer incidence in a cohort examined for allergy. Allergy 1995;50:718-22.

29 Mills PK, Beeson L, Frazer GE, et al. Allergy and cancer: organ site specific results from the Adventist health study. Am $\mathcal{F}$ Epidemiol 1992;136:287-95.

30 Cerhan JE, Wallace RB, Folsom AR, et al. Medical history risk factors for non-Hodgkin's lymphoma in older women. f Natl Cancer Inst 1997;89:314-18.

31 O'Mara BA, Byers T, Schoenfeld E. Diabetes mellitus and cancer risk: a multisite case-control study. $f$ Chron Dis 1985;38:435-41.

32 McKinney PA, Alexander FE, Roberts BE, et al. Yorkshire case control study of leukemias and lymphomas: parallel multivariate analyses of seven disease categories. Leuk Lymphoma 1990;2:67-80.

33 Adami H-O, McLaughlin J, Ekbom A, et al. Cancer risk in patients with diabetes mellitus. Cancer Causes Control 1991; $2: 307-14$

34 Mueller NE. Hodgkin's disease. In: Schottenfeld D, Fraumeni JF, eds. Cancer epidemiology and prevention. 2nd ed. New York: Oxford University Press, 1996.

35 Bernard SM, Cartwright RA, Bird CC, et al. Aetiologic factors in lymphoid malignancies: a case-control epidemiologic study. Leuk Res 1984;8:681-9.

36 Linet MS, Cartwright RA. The leukemias. In: Schottenfeld D, Fraumeni JF, eds. Cancer epidemiology and prevention. 2nd ed. New York: Oxford University Press, 1996.

37 Herrington LJ, Weiss NS, Olshan AF. Multiple myeloma. In: Schottenfeld D, Fraumeni JF, eds. Cancer epidemiology and prevention. 2nd ed. New York: Oxford University Press, 1996.

38 Devesa SS, Fears T. Non-Hodgkin's lymphoma time trends; United States and international data. Cancer Res 1992;52 (suppl):5432-40s.

39 Masala G, Di Lollo S, Picoco C, et al. Incidence rates of leukemias, lymphomas and myelomas in Italy: geographic distribution and NHL histotypes. Int $\mathcal{F}$ Cancer 1996;68: $156-9$.

40 The non-Hodgkin's lymphoma pathologic classification project: National Cancer Institute sponsored study of classifications of non-Hodgkin's lymphomas. Summary and description of a working formulation for clinical usage. Cancer 1982;49:2112-35.

41 Lukes RJ, Butler JJ. The pathology and nomenclature of Hodgkin's disease. Cancer Res 1996;26:1063-81.

42 Vineis P, Crosignani P, Sacerdote C, et al. Hematopoietic cancer and peptic ulcer: a multicenter case-control study. Carcinogenesis 1999;20:1459-63.

43 Breslow NE, Day NE, eds. Statistical methods in cancer research. Vol 1. The analysis of case-control studies. IARC Scientific Publications no 32. Lyon, France: International Agency for Reseach on Cancer, 1980

44 Vineis P, D'Amore F, and the Working Group on the Epidemiology of Hematolymphopoietic Malignancies in Italy. The role of occupational exposure and immunodeficiency in B-cell malignancies. Epidemiology 1992;3:266-70.

45 Potter M. Pathogenetic mechanisms in B-cell non Hodgkin's lymphomas in humans. Cancer Res 1992;52 (suppl): $5522-8 \mathrm{~s}$.

46 Ohshima $\mathrm{H}$, Bartsch $\mathrm{H}$. Chronic infections and inlfammatory processes as cancer risk factors : possible role of nitric oxide in carcinogenesis. Mutat Res 1994;305:253-64.

47 Pisani P, Parkin DM, Munoz N, et al. Cancer and infection: estimates of the attributable fraction in 1990. Cancer Epidemiol Biomarkers Prev 1997;6:387-400. 